\title{
Laboratory efficacy of HaNPV against pod borer, Helicoverpa armigera (Hubner) infesting chickpea
}

\section{Summary}

The experiment on laboratory efficacy of $H a \mathrm{NPV}$ against $H$. armigera infesting chickpea revealed that there was gradual increase in larval mortality along with increase in dosage of $H a \mathrm{NPV}$. The trend followed a pattern of higher the dosage of inoculum, higher was the larval mortality. All the treatments caused the mortality in $3^{\text {rd }}$ instar larvae of $H$. armigera. The highest larval mortality was obtained in the treatment of HaNPV@ @ $0.875 \mathrm{ml} / 1$ (95.52\%), which was at par with the treatment of $\mathrm{HaNPV} 0.750 \mathrm{ml} / 1(90.00 \%)$. It was also recorded that in all the treatments, higher larval mortality was recorded on $3^{\text {rd }}$ to $5^{\text {th }}$ day after treatment.

\author{
Volume 8 Issue 6 - 2018 \\ C Divya,' DM Jethva, ${ }^{2}$ HG Kanara ${ }^{3}$ \\ 'Department of Entomology, College of Agriculture, Junagadh \\ Agricultural University, India \\ ${ }^{2}$ Associate Research Scientist, Biocontrol Research Laboratory, \\ Department of Entomology, Junagadh Agricultural University, \\ India \\ ${ }^{3}$ Assistant Research Scientist, Grassland Research Station, Dhari, \\ Junagadh Agricultural University, India \\ Correspondence: C Divya, Ph.D. Student, Department of \\ Entomology, College of Agriculture, Junagadh Agricultural \\ University, Junagadh - 362 00I, Gujarat, India, \\ Email divuentomology@gmail.com
}

Received: October 13, 2018 | Published: December 19, 2018

\section{Introduction}

Among the food crops, pulses are an important group which occupies a unique position in the world of agriculture by virtue of their high protein content. The production of cereals has increased manifold in the recent past but that of pulses has remained more or less static. Insect pests are probably the main factor limiting the grain legume yields. More than 150 species of insects are known to attack pulse crops in India and of these, about 25 causes serious damage to monsoon and winter pulse crops. ${ }^{1}$ Out of them, the gram pod borer, Helicoverpa armigera (Hubner) (Lepidoptera: Noctuidae) is a most cosmopolitan and polyphagous pest which attacks numerous crops of agricultural importance and widely distributed for the tropic and sub-tropic. The indiscriminate use of pesticides for the last 40 years has almost eliminated natural enemies from many crop eco-systems, created complications of environment pollution, pest resurgence and insecticide resistance (Ma et al., 2000). This scenario has led to consider the potential of biological control as a component of pest management. Bio pesticides based on baculoviruses group especially the nucleopolyhedrosis virus (NPV) offers great scope against $H$. armigera. NPV is known for high epizootic levels and is naturally occurring obligate parasite, self- perpetuating, safe to natural enemies due to host specificity and environmental friendly.

\section{Materials and methods}

\section{Rearing of test insect on natural diet}

The culture of $H$. armigera was maintained in the laboratory for experimental purpose by making initial larval collection of $H$. armigera from chickpea field. The field - collected larvae were reared individually on chickpea pods in plastic vials under laboratory conditions. Fresh food was changed every day in morning. The larvae being pre-pupated were transferred into plastic vial containing sieved moist soil to facilitate the pupation. They were reared until the adult emergence. The newly emerged adults were transferred to a wooden cage measuring $30 \mathrm{~cm} \times 30 \mathrm{~cm}$ for oviposition. Five per cent honey solution was provided as food for moths. The freshly laid eggs were collected daily and reared till hatching in Petri dish $(15 \mathrm{~cm}$ diameter). The newly hatched larvae were used for the further study purpose.

\section{Treatment details}

\begin{tabular}{lll}
\hline Treatment no. & Treatment & Dose/ litre water \\
\hline TI & HaNPV & $0.250 \mathrm{ml} / \mathrm{l}$ \\
T2 & HaNPV & $0.375 \mathrm{ml} / /$ \\
T3 & HaNPV & $0.500 \mathrm{ml} / /$ \\
T4 & HaNPV & $0.625 \mathrm{ml} / /$ \\
T5 & HaNPV & $0.750 \mathrm{ml} / /$ \\
T6 & HaNPV & $0.875 \mathrm{ml} / /$ \\
T7 & Control & - \\
\hline
\end{tabular}

\section{Methodology}

Local strain of $H a \mathrm{NPV}$, which was commercially produced in the Bio control Research Laboratory, J.A.U. Junagadh was used for this laboratory experiment. The immature pods of chickpea grown in pots was collected and sprayed with respective treatments in the laboratory. In each treatment, six hours starved 10 larvae of the third instar were transferred into Petri dishes containing the treated immature pods and then the treatments were replicated thrice (Figure 1). The larvae were allowed to feed on the treated food for $24 \mathrm{hrs}$ and then they were provided with fresh untreated immature pods on next day.

\section{Observations recorded}

Larval mortality was recorded from 1, 2, 3, 5 and 7 days after application. The percentage of larval mortality was corrected by Abbott's formula (1925) and modified by Henderson and Tilton (1955).

Corrected percent mortality $=100 \times 1-(\mathrm{Ta} \times \mathrm{Cb} / \mathrm{Tb} \times \mathrm{Ca})$ 
Where,

$\mathrm{Ca}=$ Number of insects observed after treatment in control

$\mathrm{Ta}=$ Number of insects observed after treatment

$\mathrm{Cb}=$ Number of insects observed before treatment in control

$\mathrm{Tb}=$ Number of insects observed before treatment
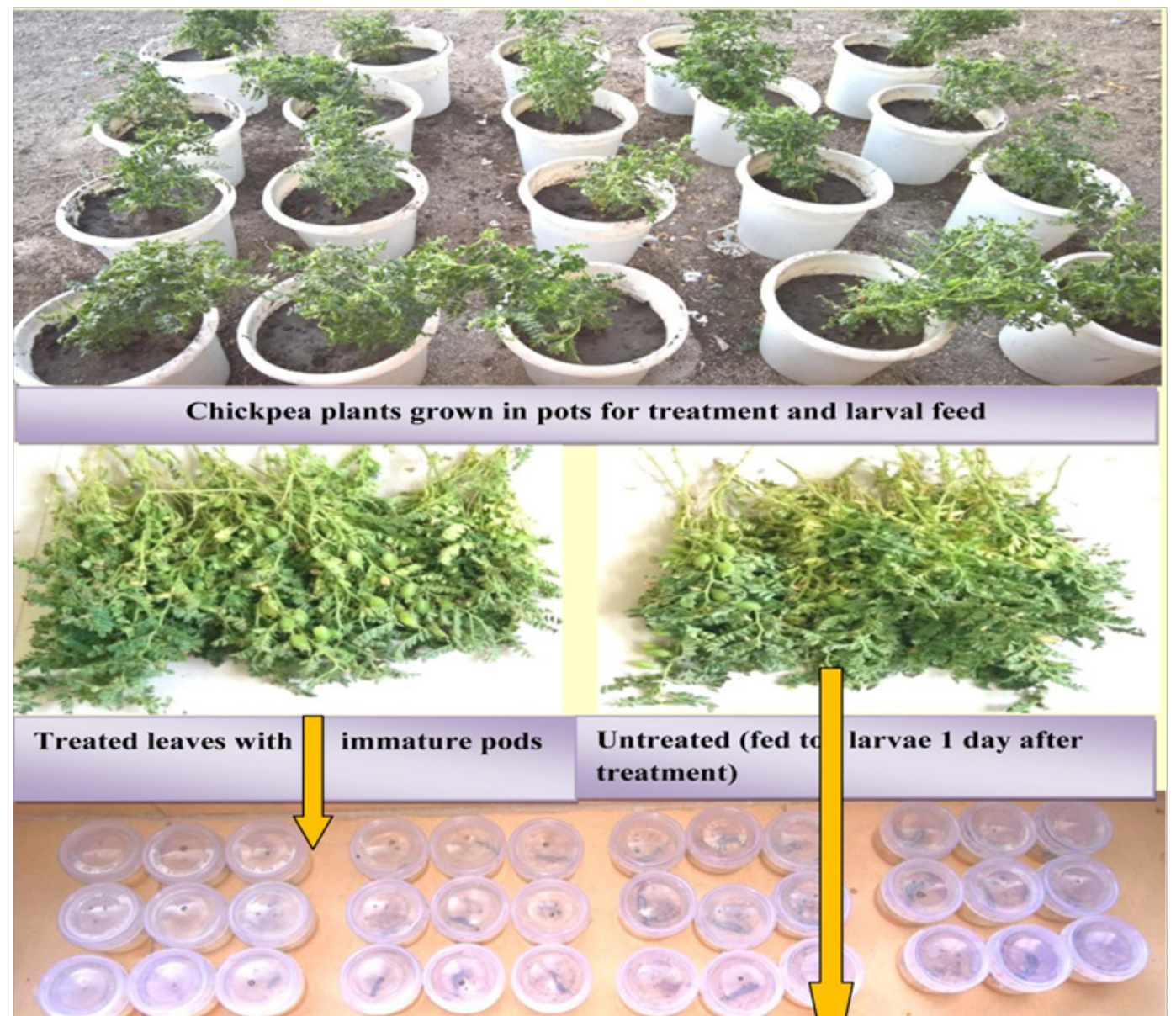

Laboratory efficacy experimental setup

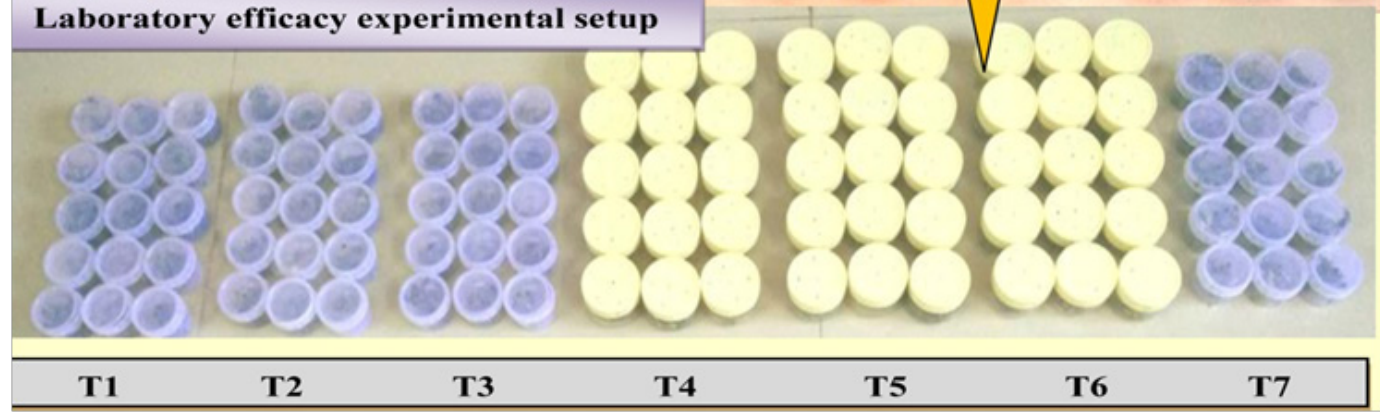

Figure I Treatment procedure for testing laboratory efficacy.

\section{Results}

\section{Effect on larval survival}

Data on instar-wise larval mortality (Plate 2) due to $\mathrm{HaNPV}$ are presented in Table 1 and depicted in Figure 2 shows the healthy and $H a \mathrm{NPV}$ infected instar wise larvae of $H$. armigera. The data showed that on first, second and third day after feeding significantly higher mortality was recorded in the first and second instar larvae as compared to third, fourth and fifth instar larvae of $H$. armigera. The mortality in the first and second instar larvae was recorded to be higher as 40.00 and $20.00 \%$ respectively, on first day after feeding, whereas, on the same day there was no mortality was recorded in fourth and fifth instar larvae. Data (Table 1) revealed that there was a consistent decrease in mortality from first to fifth instar larvae. It can also be seen that the total larval mortality among instar wise larvae ranged from 26.66 to $100.00 \%$ on eighth day after feeding. The highest mortality was recorded in the first instar larvae $(100.00 \%)$, followed by second $(70.00 \%)$, third $(56.66 \%)$, fourth $(36.66 \%)$ and fifth $(26.66 \%)$. Thus, the results clearly indicated that the first instar larvae proved to be most susceptible to $H a \mathrm{NPV}$ followed by larvae of second instar. The third instar was found moderately susceptible, while, the fourth and fifth instar larvae were found to be less susceptible to HaNPV. 


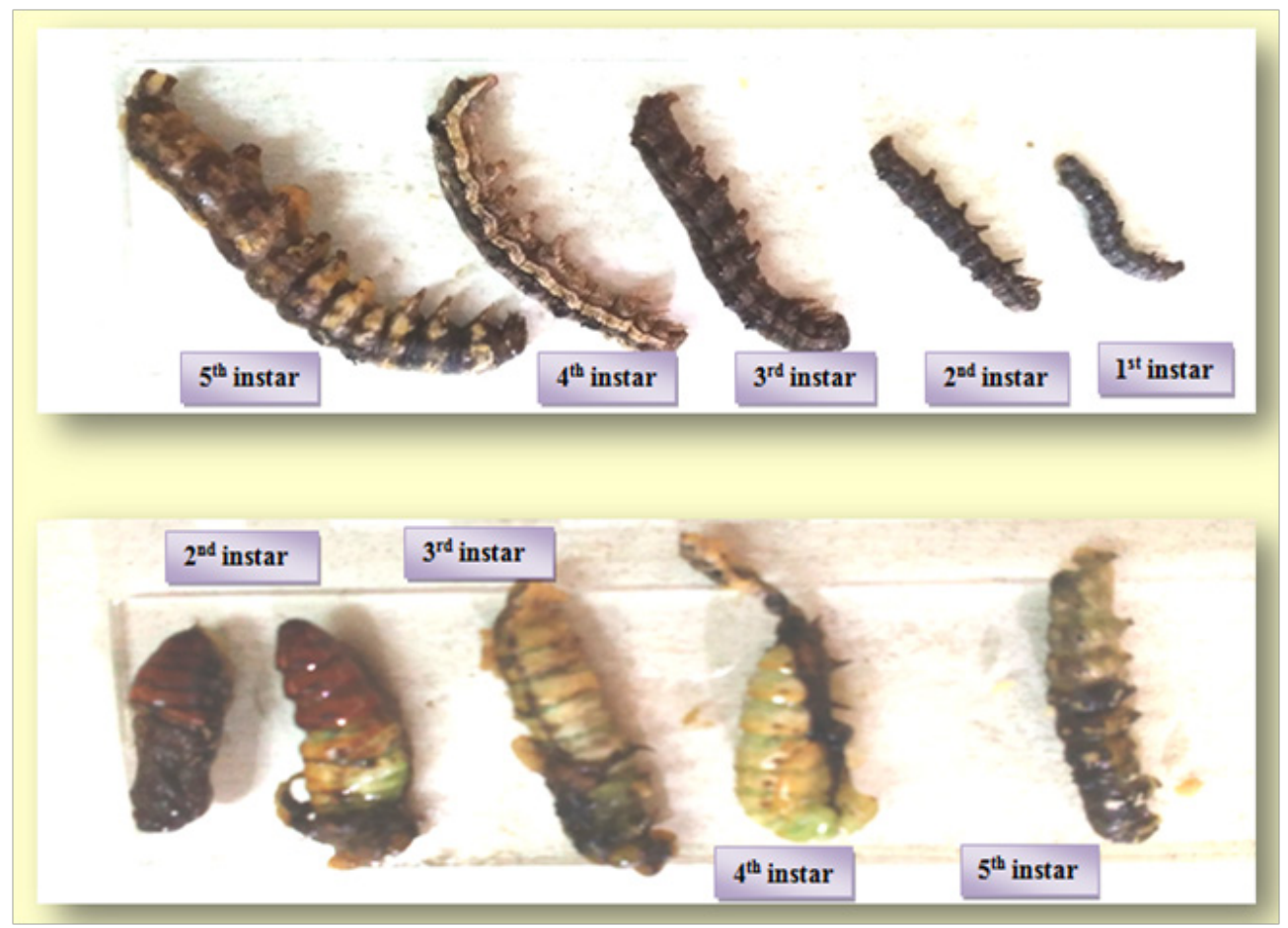

Plate II Instar-wise larva died due to HaNPV and malformed pupae.

Table I Larval mortality, pupation (\%) and cumulative mortality in $\mathrm{H}$. armigera due to HaNPV

\begin{tabular}{|c|c|c|c|c|c|c|c|c|c|c|c|}
\hline \multirow{2}{*}{$\begin{array}{l}\text { Instar } \\
\text { tested }\end{array}$} & \multicolumn{6}{|c|}{ Larval mortality (\%) after days } & \multirow{2}{*}{$\begin{array}{l}\text { Total larval } \\
\text { mortality (\%) }\end{array}$} & \multirow{2}{*}{$\begin{array}{l}\text { Pupation } \\
\text { (\%) }\end{array}$} & \multirow{2}{*}{$\begin{array}{l}\text { Pupae failed to } \\
\text { emerge (\%) }\end{array}$} & \multirow{2}{*}{$\begin{array}{l}\text { Deformed } \\
\text { adult (\%) }\end{array}$} & \multirow{2}{*}{$\begin{array}{l}\text { Cumulative } \\
\text { mortality (\%) }\end{array}$} \\
\hline & $\mathbf{I}$ & 2 & 3 & 5 & 7 & 8 & & & & & \\
\hline \multirow[t]{2}{*}{ Ist } & 39.52 & 33.52 & 18.9 & 18.9 & 18.9 & 4.05 & 90 & 0 & 4.05 & 4.05 & 100 \\
\hline & -40 & -30 & -10 & -10 & -10 & 0 & -100 & & 0 & 0 & \\
\hline \multirow[t]{2}{*}{ 2nd } & 26.92 & 18.9 & 24.25 & 21.57 & 18.9 & 4.05 & 57.1 & 30 & 18.9 & 18.9 & 90 \\
\hline & -20 & -10 & -16.66 & -13.33 & -10 & 0 & -70 & & -10 & -10 & \\
\hline \multirow[t]{2}{*}{$3 r d$} & 13.95 & 18.9 & 24.25 & 21.57 & 18.9 & 4.05 & 49.13 & 43.34 & 13.95 & 21.57 & 76.65 \\
\hline & -6.66 & -10 & -16.66 & -13.33 & -10 & 0 & -56.66 & & -6.66 & -13.33 & \\
\hline \multirow[t]{2}{*}{ 4th } & 4.05 & 9 & 18.9 & 18.9 & 21.57 & 4.05 & 37.52 & 63.34 & 21.57 & 26.92 & 69.99 \\
\hline & 0 & -3.33 & -10 & -10 & -13.33 & 0 & -36.66 & & -13.33 & -20 & \\
\hline \multirow[t]{2}{*}{ 5th } & 4.05 & 4.05 & 18.9 & 18.9 & 4.05 & 13.95 & 31.32 & 73.34 & 18.9 & 26.92 & 56.66 \\
\hline & 0 & 0 & -10 & -10 & 0 & -6.66 & -26.66 & & -10 & -20 & \\
\hline S.Em. \pm & 2.21 & 2.21 & 1.69 & 1.69 & 1.19 & 2.21 & 1.58 & - & 2.52 & 1.19 & - \\
\hline $\begin{array}{l}\text { C.D. at } \\
5 \%\end{array}$ & 6.98 & 6.98 & NS & NS & 3.76 & 6.98 & 4.99 & - & 7.93 & 3.76 & - \\
\hline CV \% & 21.66 & 22.72 & $|3.9|$ & 14.65 & 12.56 & 63.54 & 5.18 & - & 28.15 & 10.52 & - \\
\hline
\end{tabular}

Note: Data in parenthesis are original values, while outsides are angular transformed values $\left(\sin ^{-1} \sqrt{x}+0.5\right)$. 


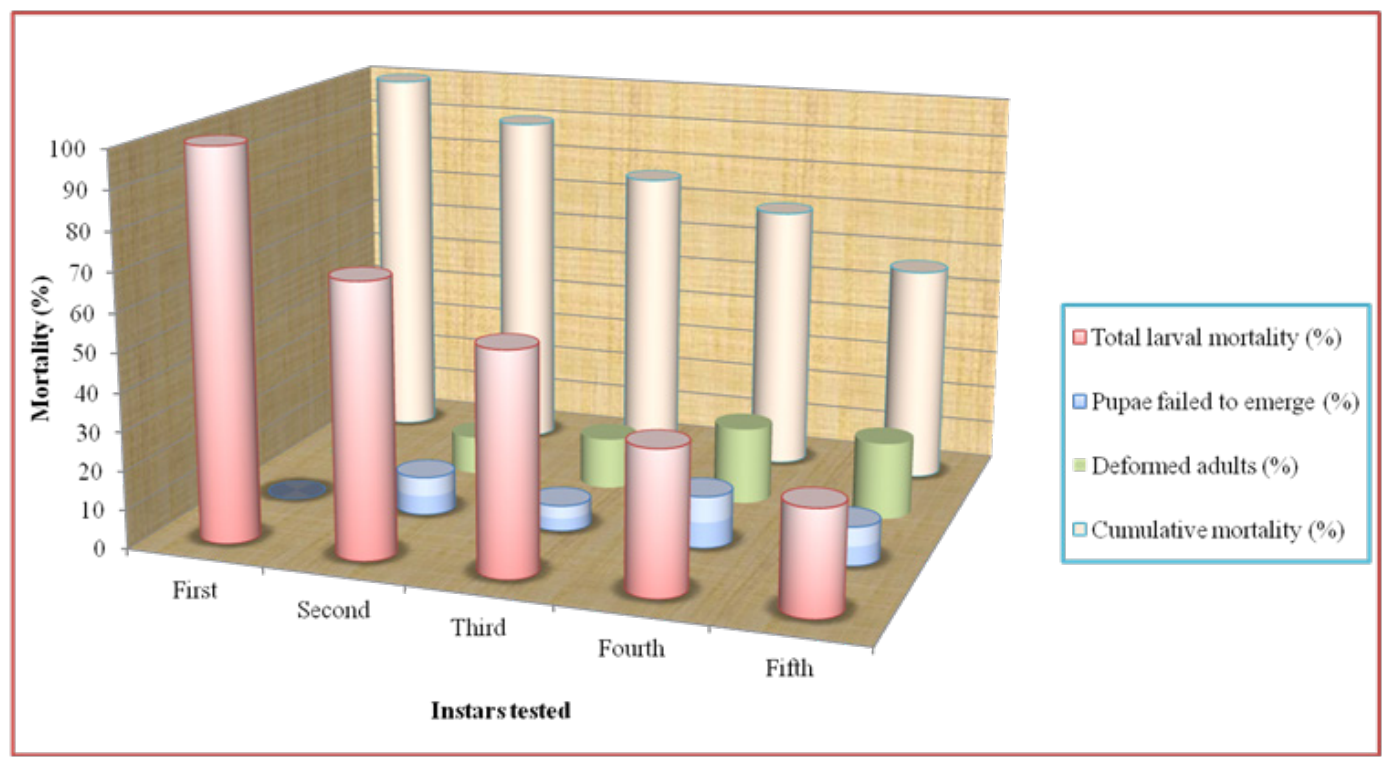

Figure 2 Larval mortality, failed pupation and adult emergence (\%) and cumulative mortality in H. armigera due to HaNPV.

\section{Effect on pupal survival}

Almost on eighth day after the treatment, larvae escaped $\mathrm{HaNPV}$ infection moved into pupal stage. The percentage of instar wise larvae succeeded for pupation was also worked out after their rearing on treated leaves with $\mathrm{HaNPV}$ and on next day they were reared on unsprayed fresh leaves. It can be seen from Table 1 that no pupa was recorded in the first instar $(0.00 \%)$. In case of second and third instar lower pupal percentage was recorded (30.00 to $43.34 \%$ ). The highest per cent of pupation was recorded in fifth instar (73.34\%), which was followed by fourth instar $(63.34 \%)$. The pupae failed to emerge into adult was also recorded and it was found to be highest in the fourth instar (13.33\%) and it was at par with second and fifth instar $(10.00 \%)$ and third instar (13.33\%). Plate 2 shows the healthy and $\mathrm{HaNPV}$ infected pupae of $H$. armigera.

\section{Effect on adult emergence}

From the data on percentage emergence of the deformed adult from pupae (Table 1) indicated that the highest percentage of deformed adults $(20.00 \%)$ was recorded in fourth and fifth instars which was followed by third instar (13.33\%). The lowest emergence of deformed adult was recorded in second in star $(10.00 \%)$.

\section{Cumulative mortality}

Data presented in Table 1 showed that the cumulative (Larval + Pupal) mortality due to $\mathrm{HaNPV}$ ranged from 56.66 to $100.00 \%$ in all the instars. The scent per cent cumulative mortality was recorded in the first in star, followed by second $90.00 \%$ ), third $(76.65 \%)$, fourth $(69.99 \%)$ and fifth in stars $(56.66 \%)$. The cumulative mortality in all the instars averaged $78.66 \%$. The present result on cumulative effect of $H a \mathrm{NPV}$, thus, showed that HaNPV@0.500ml/1 caused 56.66 to $100.00 \%$ mortality averaging $78.66 \%$ mortality in $H$. armigera on chickpea. Present study of cumulative effect of $H a \mathrm{NPV}$ against different instars of $H$. armigera showed that there was a consistent decrease in larval mortality in accordance with the five instars from day one to eight of larval rearing after one day feeding on $\mathrm{HaNPV}$ treated chickpea leaves and immature pods. The total mortality among larval instars ranged from 26.66 to $100.00 \%$ with an average of $58.00 \%$ on eighth day after feeding The larvae according to progress in instars did succeed in ascending order for pupation ( 0.00 to $73.34 \%$ ), pupae failed to emerge (6.66 to $13.33 \%$ ) and deformity of the adult (10.00 to $20.00 \%)^{2}$

\section{Conclusion}

The cumulative (Larval + pupal) mortality due to HaNPV @ 0.500 $\mathrm{ml} / 1$ ranged from 56.66 to $100.00 \%$ with an average of $78.66 \%$ in all the five instars. Thus, it is concluded from the experiment that the early instar larvae were found more susceptible than the later instars larvae. Thus, the management of the pest by spraying of $\mathrm{HaNPV}$ should be scheduled at earliest, possibly during egg stage or $1^{\text {st }}$ instar larval stage.

\section{Acknowledgments}

None.

\section{Conflicts of interest}

The authors declared there is no conflicts of interest.

\section{References}

1. Bindra OS. Insect pests of pulse crops. Indian Farming. 1968;17(11):1214.

2. Vanderzant ES. Richardson CD, Fort SW. Rearing of bollworm on artificial diet. Journal of Economic Entomology. 1962;55(1): 140. 